\title{
Development of mathematical model and optimization of GMA welding parameters of IS 2062 grade A steel weldments
}

\author{
Saadat Ali Rizvi \\ University polytechnic, Jamia Millia Islamia, New Delbi India \\ saritbhu@gmail.com, bttp:/ / orcid.org/0000-0001-2345-6789 \\ Wajahat Ali \\ SCRIET, CCS University Meerut, India \\ Wajahatali@rediffmail.com
}

ABSTRACT. In this experimental work, the effects of Gas metal arc (GMA) welding process parameters, such as arc voltage, wire feed speed, and gas flow rate on the mechanical quality of IS 2062 structural steel of grade A have been studied. Process parameters play an important role in determining the weld quality. In this research work the response surface methodology (RSM) via the design expert version 12 (DOE) software was applied to determine the weld quality, for $3 \mathrm{D}$ plot, maximize desirability for all response, and also to develop a mathematical model that can predict the main effect of the listed parameters on weld quality i.e. toughness and hardness. A set of experiments has been conducted to collect the response data using a central composite design and ANOVA was used to predict the impact of welding parameters on toughness and hardness. The obtained and predicated results were compared and it was verified that toughness and hardness of weldments are significantly affected by arc voltage and wire feed speed while gas flow rate has a minor effect.

KEYWORDS. Response surface methodology (RSM); Centre composite design (CCD); Modeling; Optimization; GMA welding; Mechanical quality.

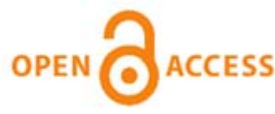

Citation: Rizvi, S. A., Ali., W., Development of mathematical model and optimization of GMA welding parameters of IS 2062 grade A steel weldments, Frattura ed Integrità Strutturale, 56 (2021) 84-93.

Received: 31.01.2021

Accepted: 17.02 .2021

Published: 01.04.2021

Copyright: (C) 2021 This is an open access article under the terms of the CC-BY 4.0, which permits unrestricted use, distribution, and reproduction in any medium, provided the original author and source are credited.

\section{INTRODUCTION}

$\mathrm{I}$

S 2062 structural steel is frequently used in fabrication industries due to its good weldability, good tensile strength (UTS), toughness, easy availability, economical etc. In this work, gas metal arc (GMA) welding process was used to join this grade A steel. Now a day's gas metal arc welding process is frequently used to weld various materials as it is a semi automatic joining process and can even be used as automatic. In GMA welding process a copper coated mild steel 
wire is used as a filler wire [1]. Several statistical and computational techniques such as response surface methodology, ANN, and Taguchi [2] techniques were applied to develop the mathematical modeling and process parameters optimization. Response surface methodology (RSM) is a powerful mathematical tool used to optimize the process parameters in processes such as machining, welding, and casting etc [3-5] and also used to develop a mathematical model [6] and it minimize the number of experiments. Muralimohan Cheepu et al [7] developed a mathematical model and optimize the welding process parameters during the laser welding of titanium alloys and compared the obtained results from response surface methodology with experimental results. Shekhar Srivastava and R.K. Garg[8] developed a mathematical model and optimized GMA welding process parameters during the welding of IS2062 via RSM approach . They verified that the wire feed speed has a significant effect, followed by arc voltage and travel speed. Sanjay A. Swami et al [9] investigated the effect of GMA welding parameters on the mechanical properties of mild steel by designing the experiments using central composite matrix. They concluded that on increasing the $\mathrm{CO}_{2}$ gas percentage in $\mathrm{Ar}$ gas ultimate tensile strength (UTS) increase up to some extend and then decreases. A G Kamble and R Venkata Rao [10] studied the effect of GMA welding process parameters on AISI 202 steel weldments and developed a model for mechanical properties and they showed in their results that higher the arc voltage decreases the hardness and mechanical quality but increases with increasing in welding speed. In the present experimental research work the effect of GMA welding process parameters on the toughness and hardness of IS2062 structural steel of grade A weldments were investigated and a mathematical model was developed by response surface methodology. Scanning electron microscopy (SEM) micromorphology fracture surface of toughness test samples was studied to determine the ductile or brittle fracture.

\section{EXPERIMENTAL PROCEDURE}

$\mathrm{I}$ $\mathrm{n}$ this research work, IS 2062 structural work of grade A in form of plate of size $300 \mathrm{~mm}$ x $60 \mathrm{~mm} \times 10 \mathrm{~mm}$ was used as parent metal. Gas metal arc (GMA) welding process was used to weld the parent metal in the shielding environment of $75 \% \mathrm{Ar}+25 \% \mathrm{CO}_{2}$ gas mixture. ER70S-6 of $\varnothing 2 \mathrm{~mm}$ is used as filler wire to join the parent metal. Chemical composition of parent metal and filler wire is mentioned in Tab. 1.

\begin{tabular}{ccccccc}
\hline Material & $\mathrm{C}$ & $\mathrm{Mn}$ & $\mathrm{S}$ & $\mathrm{P}$ & $\mathrm{Si}$ & $\mathrm{Fe}$ \\
IS 2062 & 0.22 & 1.5 & 0.049 & 0.05 & 0.37 & Bal. \\
ER70S-6 & 0.20 & 1.61 & 0.025 & 0.025 & 0.98 & Bal. \\
\hline
\end{tabular}

Table 1: Chemical composition of parent metal and filler wire (wt.\%)

Tab. 2 illustrates the different selected input parameters of GMA welding with their corresponding level, their notation, and unit in actual form. The proposed experimental design involves the variation of three factors (arc voltage, wire feed speed, and gas flow rate) at three levels. Welding trials were completely conducted based on central composite design of experiments associated with twenty numbers runs.

\begin{tabular}{cccccc}
\hline Factors & Notation & Unit & & Level \\
Arc Voltage & V & V & 25 & 26 & 27 \\
Wire feed speed & WF & IPM & 300 & 350 & 400 \\
Gas flow rate & GF & lpm & 10 & 15 & 20 \\
\hline
\end{tabular}

Table 2: Process parameters and their level

Design matrix is shown in Tab. 3. Toughness test samples before fracture and after fracture are showed in Fig. 1. 


\begin{tabular}{ccccccc}
\hline Std run & $\begin{array}{c}\text { Experimental } \\
\text { run }\end{array}$ & $\begin{array}{c}\text { Arc } \\
\text { voltage }(\mathrm{V})\end{array}$ & $\begin{array}{c}\text { Wire feed } \\
\text { speed } \\
\text { (Ipm) }\end{array}$ & $\begin{array}{c}\text { Gas flow } \\
\text { rate (lpm) }\end{array}$ & Toughness (J) & $\begin{array}{c}\text { Hardness } \\
\text { (VHN) }\end{array}$ \\
9 & 1 & 24 & 350 & 15 & 200 & 178 \\
6 & 2 & 27 & 300 & 20 & 156 & 181 \\
16 & 3 & 26 & 350 & 15 & 266 & 161 \\
5 & 4 & 25 & 300 & 20 & 188 & 186 \\
13 & 5 & 26 & 350 & 6 & 258 & 199 \\
20 & 6 & 26 & 350 & 15 & 261 & 159 \\
3 & 7 & 25 & 400 & 10 & 186 & 165 \\
1 & 8 & 25 & 300 & 10 & 242 & 171 \\
15 & 9 & 26 & 350 & 15 & 274 & 165 \\
19 & 10 & 26 & 350 & 15 & 255 & 162 \\
12 & 11 & 26 & 434 & 15 & 188 & 182 \\
2 & 12 & 27 & 300 & 10 & 214 & 196 \\
8 & 13 & 27 & 400 & 20 & 190 & 180 \\
10 & 14 & 28 & 350 & 15 & 208 & 206 \\
18 & 15 & 26 & 350 & 15 & 268 & 150 \\
4 & 16 & 27 & 400 & 10 & 192 & 181 \\
14 & 17 & 26 & 350 & 23 & 194 & 186 \\
17 & 18 & 26 & 350 & 15 & 260 & 155 \\
11 & 19 & 26 & 266 & 15 & 156 & 189 \\
7 & 20 & 25 & 400 & 20 & 202 & 175 \\
\hline & & & & & & \\
\hline
\end{tabular}

Table 3: DOE table with responses

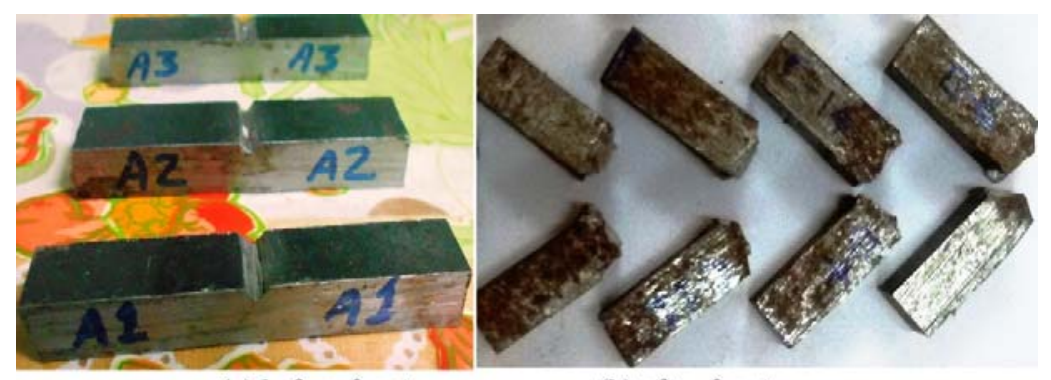

(a) before fracture

(b) after fracture

Figure 1: toughness test samples.

\section{RESULT AND DISCUSSION}

\section{Development of mathematical model}

T $\mathrm{n}$ this work arc voltage $(\mathrm{V})$, wire feed speed $(\mathrm{F})$, and gas flow rate $(\mathrm{L})$ were selected as welding process parameters. Mechanical properties, i.e. toughness and hardness of welded joints, are significantly affected by welding parameters and it is very clear from previous research work that toughness and hardness of IS 2062 steel weldments is 
considerably influenced by arc voltage and wire feed speed [11]. In regression analysis [12] as expressed by Eq. (1), an experimental mathematical model was generated in between the toughness, hardness, and independents variable [13] and check for its adequacy. Response surface methodology is also used based on central composite design (CCD) to develop a model to predict the mechanical quality and checked by ANOVA for its adequacy [14]. The mechanical properties dimensions response function can be expressed as Eqn. (1):

$$
Y_{\text {trans }}=f\left(x_{1}, x_{2}, x_{3}, x_{4}, \ldots \ldots \ldots \ldots \ldots x_{n}\right)
$$

where $Y_{\text {trans }}$ is the power transformation of the welding parameters and $x_{n}$ represent the input parameters. $x_{1}=$ arc voltage, $x_{2}=$ wire feed speed, and $x_{3}=$ gas flow rate selected as welding input parameters in this experimental work. Usually $2^{\text {nd }}$ order Eqn. (2) can be expressed [15] as:

$$
y=d_{o}+\sum_{i=1}^{k} d_{i} X_{i}+\sum_{i=1}^{k} d_{i i} X_{i}^{2}+\sum_{i}^{k} \sum_{j}^{k} d_{i j} X_{i} X_{j}+\epsilon
$$

where $\mathrm{y}$ is the response (toughness and hardness) variable, $\mathrm{x}_{\mathrm{i}}$ is the uncoated level of the variables, $\varepsilon$ is the fitting error, the coefficient $\mathrm{d}_{\mathrm{o}}$ is the constant value or intercept, and coefficients $\mathrm{d}_{\mathrm{i}}, \mathrm{d}_{\mathrm{ii}}$, and $\mathrm{d}_{\mathrm{ij}}$ represent the linear, quadratic, and interaction terms of the variable, respectively.
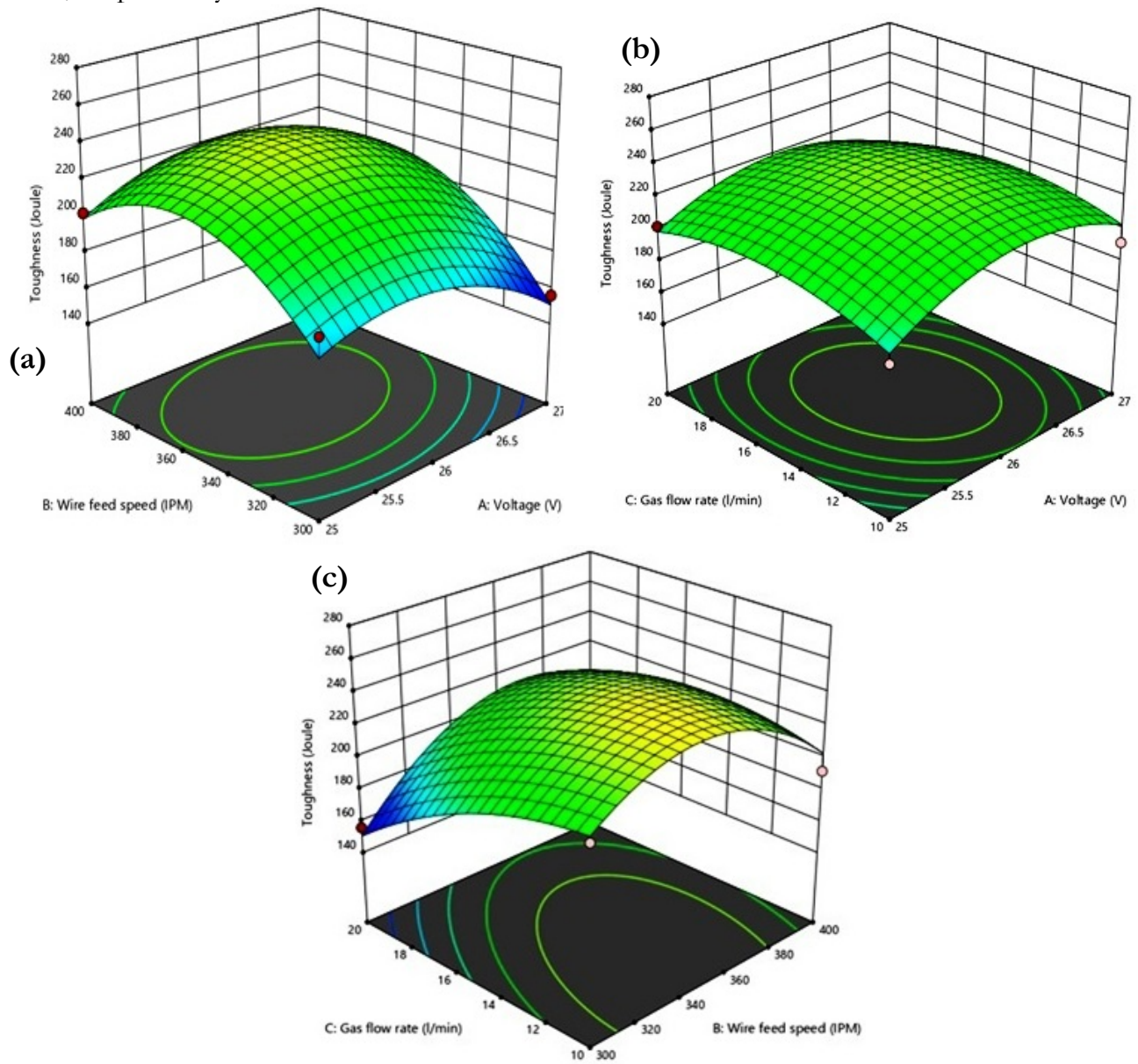

Figure 2: Response surface plot showing the interation effect of (a) WFS V V,(b) GFR Vs and V and (c) GFR Vs WFS on toughness.

\section{Effect of welding parameters on mechanical properties (toughness)}

From the Tab. 4 it is very clear that quadratic is the best possible fit for toughness. As the main interaction and quadratic factors that contribute significant to toughness include arc voltage (A), gas flow rate (B), wire feed speed (C), arc voltage 
and gas flow rate $(A B)$, arc voltage and wire feed speed $(A C)$, gas flow rate and wire feed speed(BC),current $\left(\mathrm{A}^{2}\right)$,gas flow rate $\left(\mathrm{B}^{2}\right)$, and wire fed speed $\left(\mathrm{C}^{2}\right)$.

Model for toughness

Developed mathematical model for toughness is represented by Eq.3

$$
\begin{aligned}
\text { Toughness }= & -14402.13068+1066.54705 * A+4.72138 * B+5.50615+C+0.135000 * A * B- \\
& 0.550000 * A * C+0.063000 * B * C-21.33451 * A^{2}-0.013059 * B^{2}-0.542253 * C^{2}
\end{aligned}
$$

From Fig. 2 (a) and (b) it is very clear that as on increasing the wire feed speed toughness of weldment increases up to 350 IPM after that toughness start to reduce where as on increasing the voltage toughness tends to increases and it is obtained maximum at point $26 \mathrm{~V}$ after that toughness tends to decreases it is due to increasing in the heat input.

Fig.3 (a) \& (b) repersent the normal probalility curve for toughness and hardness and this plot is used to check the adquancy of model. as all points are in a straight line, it can concluded that model is adequate[16-18].
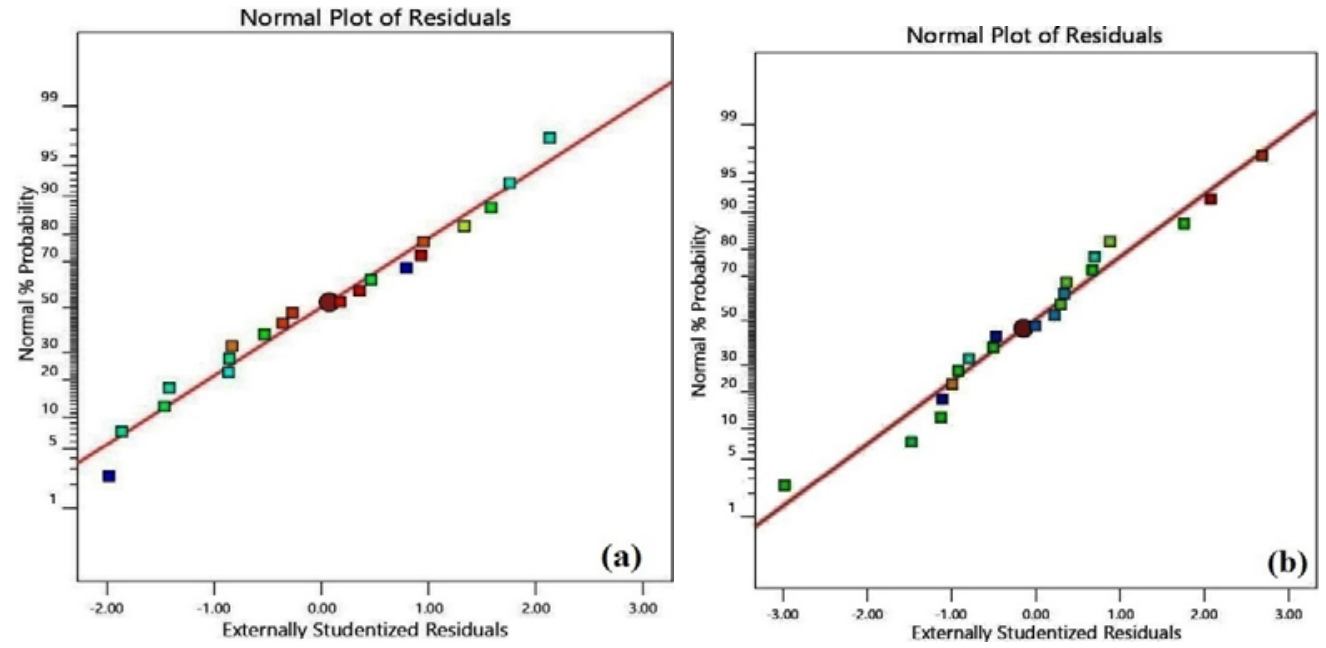

Figure 3: residuals plot for the developed model (a) toughness (b) hardness.

Design expert- 12 version software was used in this experimental work to develop and choose the suggented model that described the response factor in regression analysis and sequential $\mathrm{F}$ test was performed to test the significence of the regression model and determine the significent model terms of developed model. Data of Tab. 4 and 5 indicate that a quadratic model is statstically significant for the weldments mechancial quality i.e. toughness and hardness and can be used for further analysis in this investigation.

\begin{tabular}{cccccc}
\hline Source & Sequential p-value & Lack of Fit p-value & Adjusted R $^{\mathbf{2}}$ & Predicted R $^{\mathbf{2}}$ & \\
Linear & 0.5587 & 0.0002 & -0.0476 & -0.2908 & \\
2FI & 0.7135 & 0.0001 & -0.1650 & -1.0345 & \\
Quadratic & $<0.0001$ & 0.0505 & 0.9088 & 0.6829 & Suggested \\
Cubic & 0.0162 & 0.8845 & 0.9746 & 0.9803 & Aliased \\
\hline
\end{tabular}

Table 4: Statistics model for toughness test

\begin{tabular}{ccccccc}
\hline Source & Sum of Squares & df & Mean Square & F-value & p-value & \\
Mean vs Total & $9.496 \mathrm{E}+05$ & 1 & $9.496 \mathrm{E}+05$ & & & \\
Linear vs Mean & 3340.00 & 3 & 1113.33 & 0.7125 & 0.5587 & \\
2FI vs Linear & 2409.50 & 3 & 803.17 & 0.4622 & 0.7135 & \\
Quadratic vs 2FI & 21231.24 & 3 & 7077.08 & 52.00 & $<0.0001$ & Suggested \\
Cubic vs Quadratic & 1134.00 & 4 & 283.50 & 7.49 & 0.0162 & Aliased \\
Residual & 227.06 & 6 & 37.84 & & & \\
Total & $9.780 \mathrm{E}+05$ & 20 & 48897.50 & & & \\
\hline
\end{tabular}

Table 5: Sequential model sum of square for toughness model. 
Analysis of variance (ANOVA)

ANOVA is a power full statically tool to determine which factor influence the response [19]. A model or model term is significant when $\mathrm{p}$ value is less than 0.05. In ANOVA p-term represent the probability of importance for each control parameters and higher signifies the use fullness of that parameters. Importance of design or control parameters can be determined and confirmed by ANOVA [20]. Tabs. 6 and 7 shows the ANOVA table for toughness and hardness of weldment. For both cases quadratic model was suggested. For both cases, as the value of $\mathrm{R}^{2}$ is closer to 1 hence model is accepted.

\begin{tabular}{|c|c|c|c|c|c|c|}
\hline Model & 26980.75 & 9 & 2997.86 & 22.03 & $<0.0001$ & significant \\
\hline A-Voltage & 202.17 & 1 & 202.17 & 1.49 & 0.2509 & \\
\hline B-Wire feed speed & 41.54 & 1 & 41.54 & 0.3052 & 0.5928 & \\
\hline C-Gas flow rate & 3096.29 & 1 & 3096.29 & 22.75 & 0.0008 & \\
\hline $\mathrm{AB}$ & 364.50 & 1 & 364.50 & 2.68 & 0.1328 & \\
\hline AC & 60.50 & 1 & 60.50 & 0.4445 & 0.5200 & \\
\hline $\mathrm{BC}$ & 1984.50 & 1 & 1984.50 & 14.58 & 0.0034 & \\
\hline $\mathrm{A}^{2}$ & 6559.46 & 1 & 6559.46 & 48.19 & $<0.0001$ & \\
\hline $\mathrm{B}^{2}$ & 15361.09 & 1 & 15361.09 & 112.86 & $<0.0001$ & \\
\hline $\mathrm{C}^{2}$ & 2648.42 & 1 & 2648.42 & 19.46 & 0.0013 & \\
\hline Residual & 1361.05 & 10 & 136.11 & & & \\
\hline Lack of Fit & 1135.05 & 5 & 227.01 & 5.02 & 0.0505 & not significant \\
\hline Pure Error & 226.00 & 5 & 45.20 & & & \\
\hline \multirow[t]{4}{*}{ Cor Total } & 28341.80 & Std. Dev. & 11.67 & & $\mathrm{R}^{2}$ & 0.9520 \\
\hline & & Mean & 217.90 & & Adjusted $\mathrm{R}^{2}$ & 0.9088 \\
\hline & & C.V. $\%$ & 5.35 & & Predicted $\mathrm{R}^{2}$ & 0.6829 \\
\hline & & & & & Adeq Precision & 13.7511 \\
\hline
\end{tabular}

Table 6: ANOVA table for toughness.

\begin{tabular}{|c|c|c|c|c|c|c|}
\hline Model & 3574.75 & 9 & 397.19 & 4.83 & 0.0108 & significant \\
\hline A-Voltage & 568.20 & 1 & 568.20 & 6.91 & 0.0252 & \\
\hline B-Wire feed speed & 146.78 & 1 & 146.78 & 1.79 & 0.2110 & \\
\hline C-Gas flow rate & 12.12 & 1 & 12.12 & 0.1474 & 0.7090 & \\
\hline $\mathrm{AB}$ & 0.1250 & 1 & 0.1250 & 0.0015 & 0.9697 & \\
\hline AC & 210.13 & 1 & 210.13 & 2.56 & 0.1409 & \\
\hline $\mathrm{BC}$ & 10.13 & 1 & 10.13 & 0.1232 & 0.7329 & \\
\hline $\mathrm{A}^{2}$ & 1204.41 & 1 & 1204.41 & 14.66 & 0.0033 & \\
\hline $\mathrm{B}^{2}$ & 674.99 & 1 & 674.99 & 8.21 & 0.0168 & \\
\hline $\mathrm{C}^{2}$ & 1251.44 & 1 & 1251.44 & 15.23 & 0.0029 & \\
\hline Residual & 821.80 & 10 & 82.18 & & & \\
\hline Lack of Fit & 676.47 & 5 & 135.29 & 4.65 & 0.0584 & not significant \\
\hline Pure Error & 145.33 & 5 & 29.07 & & & \\
\hline \multirow[t]{5}{*}{ Cor Total } & 4396.55 & & & & & \\
\hline & & Std. Dev. & 9.07 & & $\mathrm{R}^{2}$ & 0.8131 \\
\hline & & Mean & 176.35 & & Adjusted $\mathrm{R}^{2}$ & 0.6449 \\
\hline & & C.V. $\%$ & 5.14 & & Predicted $R^{2}$ & -0.2269 \\
\hline & & & & & Adeq Precision & 6.5677 \\
\hline
\end{tabular}

Table 7: ANOVA table for hardness 


\section{Effect of welding parameters on mechanical properties (hardness)}

The moderate fit for hardness (VHN) also highlighted the quadratic relation as the possible best fit. From ANOVA table it is clear that as the main interaction and quadratic factors that contribute significant to hardness include arc voltage (A), gas flow rate $(B)$, wire feed speed $(C)$, arc voltage and gas flow rate (AB), arc voltage and wire feed speed (AC), gas flow rate and wire feed speed $(B C)$, current $\left(A^{2}\right)$, gas flow rate $\left(B^{2}\right)$, and wire fed speed $\left(C^{2}\right)$.reduced ANOVA is tabulated in Tab. 7. Developed mathematical model for hardness is represented by Eq.4.

$$
\begin{aligned}
H V= & +6262.89689-454.42813 * A-2.11433 * B+13.70422 * C+0.002500 * A * B- \\
& 1.02500 * A * C+0.004500 * B * C+9.14189 * A^{2}+0.002738 * B^{2}+0.372747 * C^{2}
\end{aligned}
$$

From Fig. 4 (a) and (b) it is very clear that as on increasing the arc voltage there is increment in the hardness of weldment where as on increasing the wire feed speed and gas flow rate there is little increment in the hardness. but from Fig. 4 (c) it is very clear on increasing the amount of gas flow rate hardness of weldment first increases and then decreases.
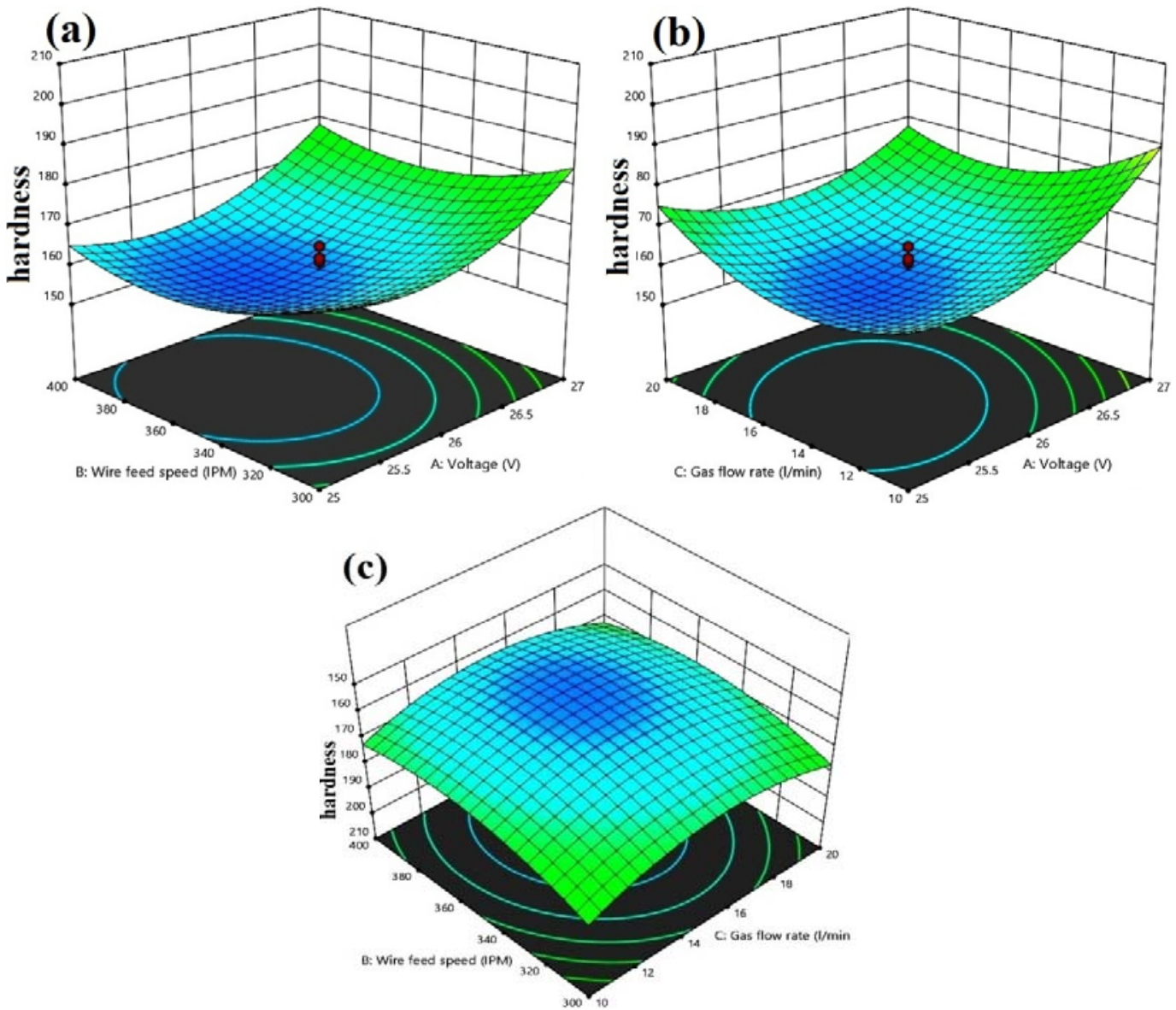

Figure 4: Response surface plot showing the interation effect of (a) WFS Vs V,(b) GFR Vs and V and (c) GFR Vs WFS on hardness.

Fig. 5 shows the effect of all the three welding process parameters on the weldment hardness at the centre point in the dsign space.

\section{Fractographic analysis}

Toughness test samples of IS 2062 steel weldments were tested for mode of fracture with the support of scanning electron microscope (SEM) to determine the nature of fracture i.e. ductile fracture of brittle fracture and it was observed that from Fig. 6 a- b having quasi-cleavage fracture [21] that consist a river patter and shows a brittle fracture but from Fig. $6 \mathrm{c}$ it is very clear as there are a large number of dimples on fracture surface hence representing a ductile fracture. 


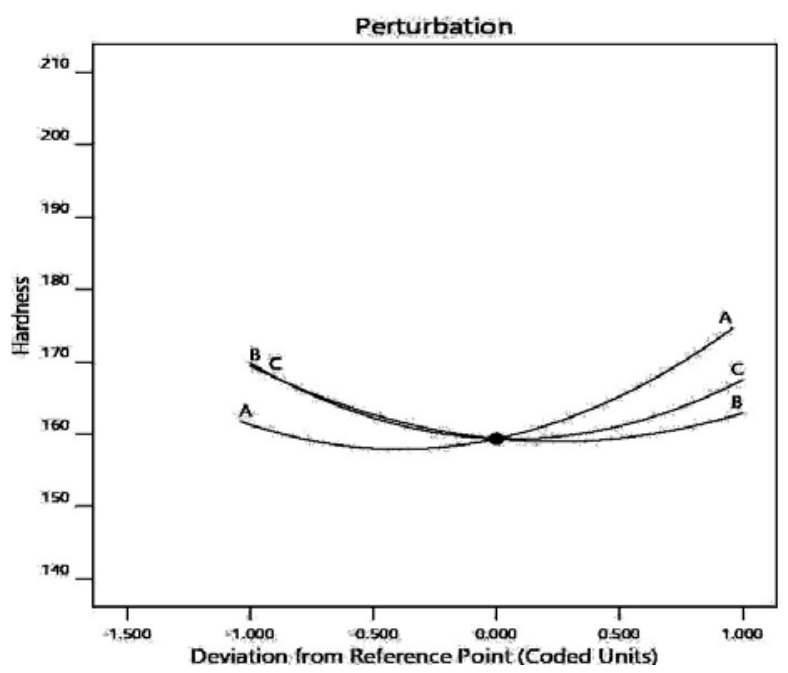

Figure 5: Perturbation plot showing the effect of all factor on the hardness of weldment.

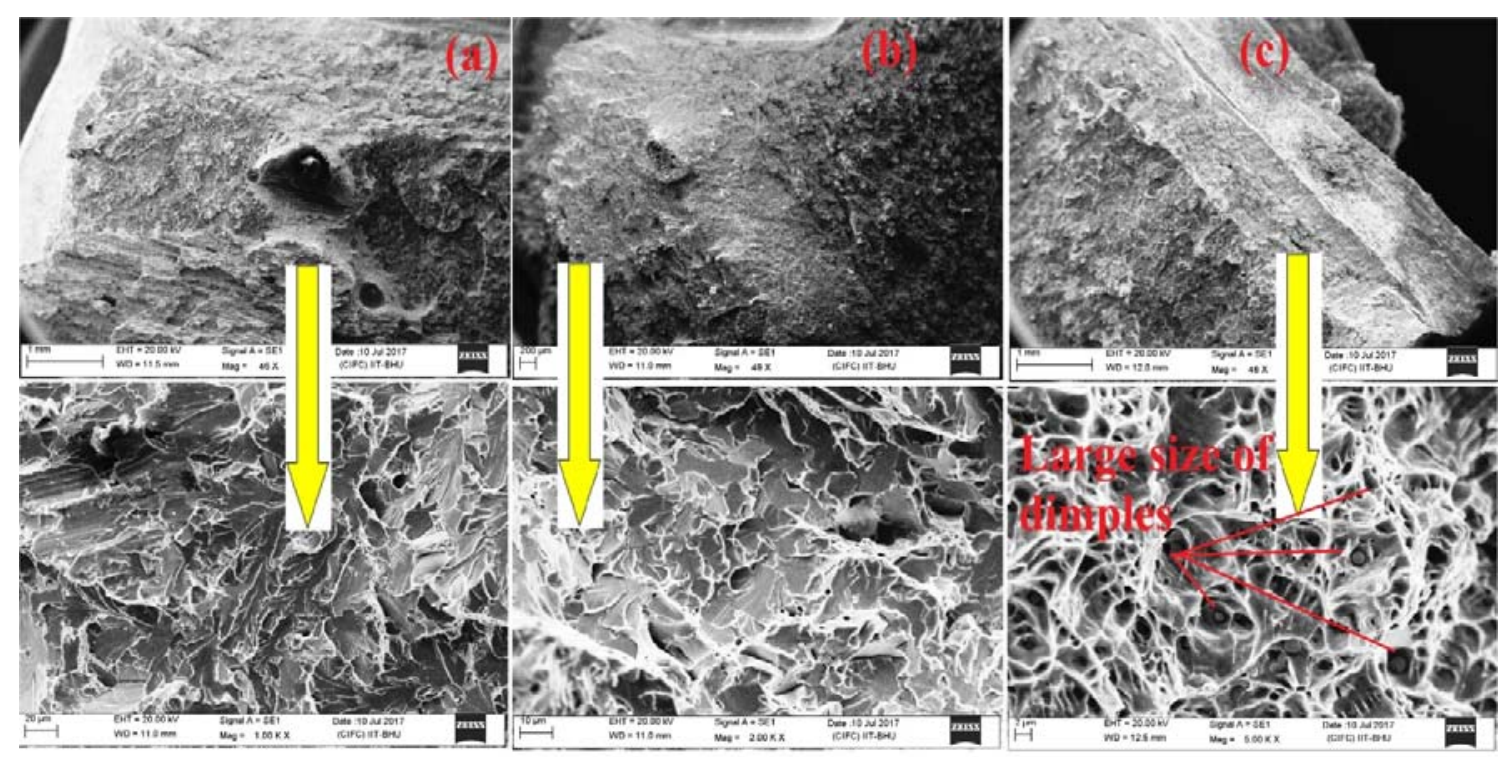

Figure 6: SEM image of fracture surface of samples.

\section{CONCLUSION}

7 his experimental work focuses on the GMA welding of IS 2062 structural steel of grade A. This study was carried out in order to determine the effect of GMA welding process parameters on the mechanical quality of weldments i.e. toughness and hardness. In addition, the interactions between the welding parameters were determined via 3D response plot and a mathematical model was proposed to predict the mechanical behavior of the weldments using response surface methodology (RSM). The following conclusions have achieved.

$>$ Response surface methodology approach can be effectively applied to determine the effect of process parameters on response i.e. on output.

$>$ RSM method is also used to plot the contour graph for various responses to show the interaction between the different process parameters.

$>$ The effective of both models i.e. toughness and hardness was checked according to $\mathrm{R}^{2}$ terms. As the $\mathrm{R}^{2}$ value in model is near to unity hence developed model represent good accuracy.

$>$ Ductile fracture was observed on SEM fractrography of toughness test samples 
Wire feed speed and arc voltage having the significant effect on toughness and hardness. Gas flow rate is least effective parameters.

\section{REFERENCES}

[1] Rizvi, S. A., Ali, W. (2009). A text book of advanced welding technology, Kataria \& Sons (P) Ltd New Delhi, 55.

[2] Rizvi, S. A., Ali, W. (2020). Multi attribute decision making parametric optimization in weld bead by gas metal arc welding through grey relation analysis: A case study, International Journal of Engineering, Science and Technology,12(2) 2020, pp. 59-66. DOI:10.4314/ijest.v12i2.7.

[3] Kuntoğlu, M., Aslan, A., Pimenov, D. Y., Giasin, K., Mikolajczyk, T., Sharma, S. (2020). Modeling of cutting parameters and tool geometry for multi-criteria optimization of surface roughness and vibration via response surface methodology in turning of AISI 5140 steel, Materials (Basel), 13(19) 4242, pp. 1-21. DOI: 10.3390/ma13194242.

[4] Safeen, W., Hussain, S. Wasim, A., Jahanzaib, M., Aziz, H., Abdalla, H. (2016). Predicting the tensile strength, impact toughness, and hardness of friction stir-welded AA6061-T6 using response surface methodology, International journal of advanced manufacturing technology, 87, pp. 1765-1781. DOI 10.1007/s00170-016-8565-9.

[5] Aliemeke, B.N.G., Oladeinde, M. H. (2020). Box-behnken design optimization of sand casting orocess parameters, International Journal of Engineering Technologies, 6(2), pp. 25-36. DOI:10.19072/ijet.714473

[6] Zhao, D., Bezgans, Y., Vdonin, N., Du, W. (2021). The use of TOPSIS-based-desirability function approach to optimize the balances among mechanical performances, energy consumption, and production efficiency of the arc welding process, International Journal of Advanced Manufacturing Technology, pp. 1-15.

DOI: 10.1007/s00170-021-06601-w.

[7] Cheepu, M., Venkateswarlu, D., Nageswara Rao, P., Senthil Kumaran, S., Srinivasan, N. (2019). Optimization of Process Parameters Using Surface Response Methodology for Laser Welding of Titanium Alloy, Materials Science Forum, 969, pp. 539-545. DOI:10.4028/www.scientific.net/MSF.969.539

[8] Srivastava, S., Garg, R.K. (2017). Process parameter optimization of gas metal arc welding on IS: 2062 mild steel using response surface methodology, Journal of Manufacturing Processes 25, pp. 296-305.

DOI: 10.1016/j.jmapro.2016.12.016.

[9] Swami, S. A., Jadhav, S. M., Deshpande, A. (2016). Influence of MIG Welding Process Parameters on Tensile Properties of Mild Steel, JERS, European Journal of Engineering Research and Science 1(2), pp. 1-5.

[10] Kamble, A. G., Venkata Rao, R, (2017). Effects of process parameters of GMAW on bead geometry, tensile strength, hardness, microstructure and thermo-mechanical simulation of AISI 202 steel, Indian Journal of Engineering \& Materials Sciences, 24(6), pp. 413-428.

[11] Rizvi, S. A., Ali, W. (2016). Application of Taguchi technique to optimize the process parameters of MIG wedging on IS2062 steel, International Journal on Emerging Trends in Mechanical \& Production Engineering, 2(2), pp. 1-11.

[12] Kumar, A., Sharma, R. (2020). Multi-response optimization of magnetic field assisted EDM through desirability function using response surface methodology, Journal of the Mechanical Behavior of Materials 29, pp. 19-35. DOI:10.1515/jmbm-2020-0003

[13] Choudhary, A., Kumar, M., Rajen.dra Unune, D. (2019). Experimental optimization of weld bead characteristics during submerged arc welding of AISI 1023 steel, Defence Technology 15, pp. 72—82. DOI:10.1016/j.dt.2018.08.004.

[14] Xu, W. H., Lin, S. B., Fan, C. L., Yang, C. L. (2015). Prediction and optimization of weld bead geometry in oscillating arc narrow gap all-position GMA welding, International Journal of Advanced Manufacturing Technology 79, pp. 183196. DOI:10.1007/s00170-015-6818-7.

[15] Xu, J., Yan, F., Li , Y., Yang, Z., Li, L. (2020). Multiobjective optimization of milling parameters for ultrahigh-strength steel AF1410 based on the NSGA-II method, Advances in Materials Science and Engineering 3, pp. 1-11. DOI:10.1155/2020/8796738.

[16] Sada, S. O. (2018). Optimization of weld strength properties of Tungsten inert gas mild steel welds using the response surface methodology, Nigerian Journal of Technology (NIJOTECH), 37(2), pp. 407 - 415. DOI:10.4314/njt.v37i2.15.

[17] Nakhaei, M. R., Mostafa Arab, N. B., Naderi, G. (2013). Application of response surface methodology for weld strength prediction in laser welding of polypropylene/clay nanocomposite, Iran Polymer Journal 22, pp. 351-360.

DOI 10.1007/s13726-013-0134-6.

[18] Aslantas, K., Danish, M., Hasçelik, A., Mia, M., Gupta, M., Ginta, T., Ijaz, H. (2020). Investigations on surface roughness and tool wear characteristics in micro-turning of Ti-6Al-4V alloy, Materials, 13(13), pp. 1-20. 
DOI:10.3390/ma13132998

[19] Rizvi, S. A. (2018). Application of Taguchi technique to optimize the GMA welding parameters and study of fracture mode characterization of AISI 304H welded Joints, Int. Rev. Appl. Sci. Eng. 9 (1), pp. 9-16. DOI: $10.1556 / 1848.2018 .9 .1 .2$

[20] Mia, M., Dey, P.R., Hossain, M.S., Arafat, Md. T., Asaduzzaman, Md., Shoriat Ullah, Md., Zobaer, S.M.T. (2018). Taguchi $\mathrm{S} / \mathrm{N}$ based optimization of machining parameters for surface roughness, tool wear and material removal rate in hard turning under MQL cutting condition, Measurement, 122, pp. 380-391.

DOI: 10.1016/j.measurement.2018.02.016.

[21]Juan, W., Yajiang, L., Peng, L. (2003). Effect of weld heat input on toughness and structure of HAZ of a new superhigh strength steel, Bull. Mater. Sci., 26(3), pp. 301-305. 